\title{
Artificial Neural Networks as Tools for Controlling Production Systems and Ensuring Their Stability
}

\author{
Anna Burduk \\ Wrocław University of Technology, 27 Wybrzeże Wyspiańskiego St., \\ 50-370 Wrocław, Poland \\ anna .burduk@pwr .wroc.pl
}

\begin{abstract}
Models of artificial neural networks can be used to control a production system, and thus to ensure its stability. Such models are very useful tools, because they can be built quickly and easily. The only issue is a large amount of data needed in the neural network training process. However, in the era of common availability of IT systems, the parameterization and standardization of production processes is not a problem anymore. Contemporary production systems are mostly automated and metered. This paper presents a method for building a model of an artificial neural network for controlling a wire harness production system and determining its stability.
\end{abstract}

Keywords: production system, production process stability, neural networks.

\section{Introduction}

A contemporary customer requires that a product should be not only of good quality and sold at a low price, but also diversified, i.e. available in different versions and variants. In order to meet these requirements, manufacturers are forced to manufacture products in small batches and quickly deliver them to the market. However, a problem with ensuring the stability of production appears here. Production in small batches with highly diversified products and low inventory levels is characterised by a much lower stability as compared with the large-batch manufacturing. Although these disturbances are usually temporary, they may lead to a loss of the functioning or manufacturing stability in a company, which in turn translates into financial losses as well as a loss of customers [5].

In order to ensure smooth functioning of a production system, the stability of its processes must be ensured and, on the other hand, quick decisions, which would be encumbered with the lowest possible risk and uncertainty, should be made. The concept of stability is derived from systems theory and means the ability of a system to return to the steady state after the disturbances have ceased. The assessment of the system stability is a typical task of the qualitative analysis. Stability in a very broad sense means permanency (invariability over time) of a system feature or a certain series of states of the system $[4,6]$. 
The steady state is a system state that meets certain conditions. Each system is in a certain state, and because production systems are of dynamic character, a continuous transformation, which causes transition from one state to another, takes place in them. In other words, parameters of a production process may have a different value at any moment $[4,7]$. Taking into account any time interval (provisionally adopted unit), it can be said that there is a sequence of output or input states.

When transposing the definition of stability to production systems it can be said that a production system may be considered stable if values of the parameters defining it are within the ranges defined in the planning function and registered in a standard (usually a production plan). Steady state of a production system is presented in Fig. 1.

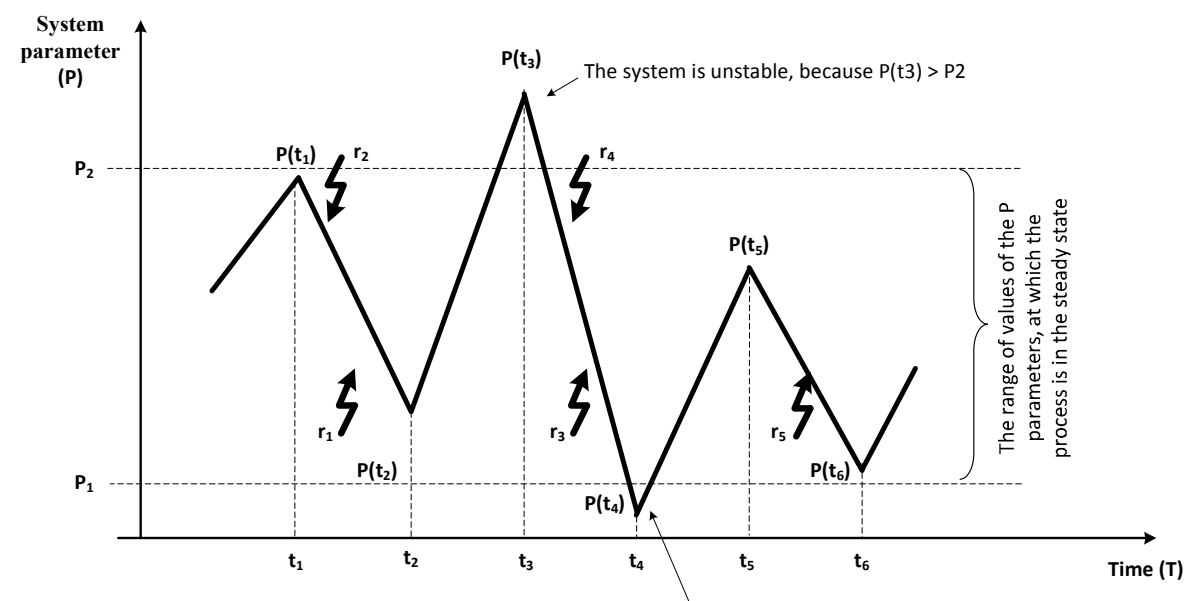

Fig. 1. Steady state of a system

If the value of the parameter $P_{i}$ in the instant $t_{i}$ is within a defined range, that is $P_{1} \leq P_{i} \leq P_{2}$, it proves that the course of the process is correct. Otherwise, corrective measures should be taken. Corrective measures usually consist in changing the values of control variables (inputs to the system X) in such a way, so that the values of the parameters characterizing the controlled variables (outputs from the system Y) return to the process course standards established in the planning function. A correct decision will cause that the system will return to the steady state $[3,8]$.

In connection with the above, the stability of a production system at the assumed margin of variability will be understood as maintaining the steady state by the system for a certain assumed period. A production system is in the steady state, if values of the parameters characterizing the system are within the ranges defined in the planning function and registered in a standard (usually a production plan).

Production systems are not only of technical nature, but also of economic character, and one of their purposes is to generate profit through a continuous increase of the market share. If the development and an increase in the market share are included in company's plans, the stability of a production system should be then understood as the ability to maintain or increase the values assumed in the parameters plans. 


\section{$2 \quad$ Artificial Neural Networks in Production System Control}

Decisions are based on objectives with different planning perspectives, while possible variants are verified on various types of models of products, processes and even entire systems. A model is a simplified representation of the reality. It constitutes the main source of knowledge about the object being modelled and the impact of planned solution on the object. A model describes and explains the method of operation and functioning of an object or a system under specific conditions. Studies performed on a model do not cause disturbances in the functioning stability of a real object or system. It offers the possibility to verify the effects of the decisions planned both in relation to the current operations of an enterprise and its future $[1,2,9]$.

Usability of models is influenced by their accuracy, possibility of populating them with reliable data, and a short time of building them. It is possible thanks to the progressing unification, standardization and parameterization of production processes and products. Standardization, apart from shortening the time needed to build a model, also lowers the costs of product development or production process improvement.

In the case of management or optimization of a production process, a model is used to verify the decisions planned. Thanks to the use of IT systems, a model can be populated with appropriate data from a real system. Experiments conducted on a model in a way that does not disturb the functioning of the real system allow learning about the effects and selecting the most optimal decision variant concerning the quantities and types of inputs to the system.

The entire 19th century and most of the 20th century are characterized by predominance of mathematical modelling. Such methods usually allow obtaining good results from models, however the complexity and dynamics of contemporary enterprises cause that there is a need to look for new modelling methods such as artificial neural networks (ANN, NN). They belong to the group of so-called empirical modelling techniques, and the main issue associated with them is to provide measurement data. In the computerized environment of today's companies, a lack of data is not a problem, because most of them have different types of IT systems, while production processes are generality metered and automated. It can be said that companies often have a problem not with a lack of data but with their excess.

In turn, the market requirements and the dynamics of the business environment caused that new, faster methods of production system modelling are searched for. Such methods include models of artificial neural networks, which provide solutions that take into account the process of learning on the basis of available data. They allow skipping the stage of modelling complex relationships between elements of a production system. In order to build a model of a production system, it is enough to define the problem: selection of input and output variables, and a set of training data.

Artificial neural networks are usually used to solve problems related to approximation, interpolation, prediction, classification, recognition, and control. Image recognition, which also includes classification, grouping and processing, accounts for approx. $70 \%$ of all industrial applications. In the management and operation of production systems, artificial neural network are more and more often used for $[1,9,10,11]$ : 
- control of production processes, robots,

- analysis of manufacturing problems,

- diagnostics of electronic systems of machines,

- selection of personnel and input materials,

- optimization of the business activity, waste disposal, robot movements,

- planning overhauls of machines,

- forecasting.

The primary objective of modelling the dynamics of a production process is to identify the temporal variability of its physical quantities or states. To this end, a time series, i.e. an ordered sequence of values of a certain variable over time, should be determined. A time series may have a form of a vector $\left[y\left(t_{1}\right), y\left(t_{2}\right), \ldots, y\left(t_{N}\right)\right]$. Due to the fact that process parameters may differ in separate phases of the process, the time series vector can take the form of a vector defined in $\mathrm{N}$-dimensional space. Individual components of this vector will be the states of the production process stages in the past, which in turn can be regarded as points in a multi-dimensional output space. Thus the task of analysing the temporal variability of the production process can be reduced to searching $\mathrm{N}$-dimensional space for a certain trajectory, on which the analysed output variable of the process "moves". Therefore, a given quantity in the form of a time series is determined in order to predict its value in future moments $[2,10]$.

\section{A Multilayer Perceptron Network for Determining the Stability of the Wire Harness Assembly Process}

\subsection{Characteristics of the Wiring Harness Assembly Process}

A growing company producing wiring harnesses for Electrolux dishwashers planned to increase the production plan by 30 to $40 \%$ in the coming years to meet the increasing orders. An extension of the production program will lead to an increase in the load on production resources, while the production system will be more vulnerable to disturbances and risk factors occurring at the production line.

The analysed factory manufactures approximately 700 different types of products. All the products are characterized by a high similarity of the structure and the manufacturing process. Each wiring harness consists of so-called modules, while a module - of wires ended with terminals. Both the number of modules and the number of wires may differ depending on the type of wiring harness. Some wires may be joined with the use of insulating tape. Individual modules are connected in the enclosure.

Control in the analysed production system takes place according to the rules applicable for a pull control system. The process is stimulated by assembly centres. The assembly takes place in three centres operating in parallel. Material flow in the assembly centre is presented in 
a)

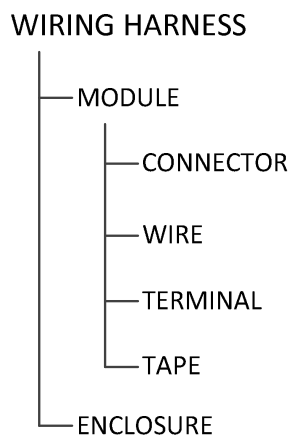

b)

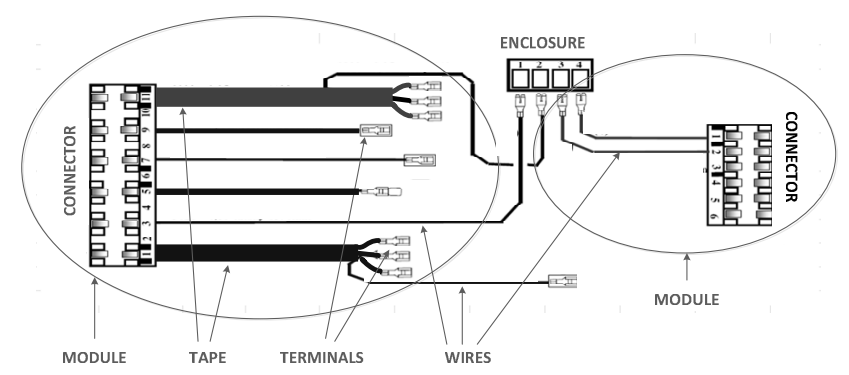

Fig. 2. a) Structure of a wiring harness, b) schematic diagram of the selected wiring harness

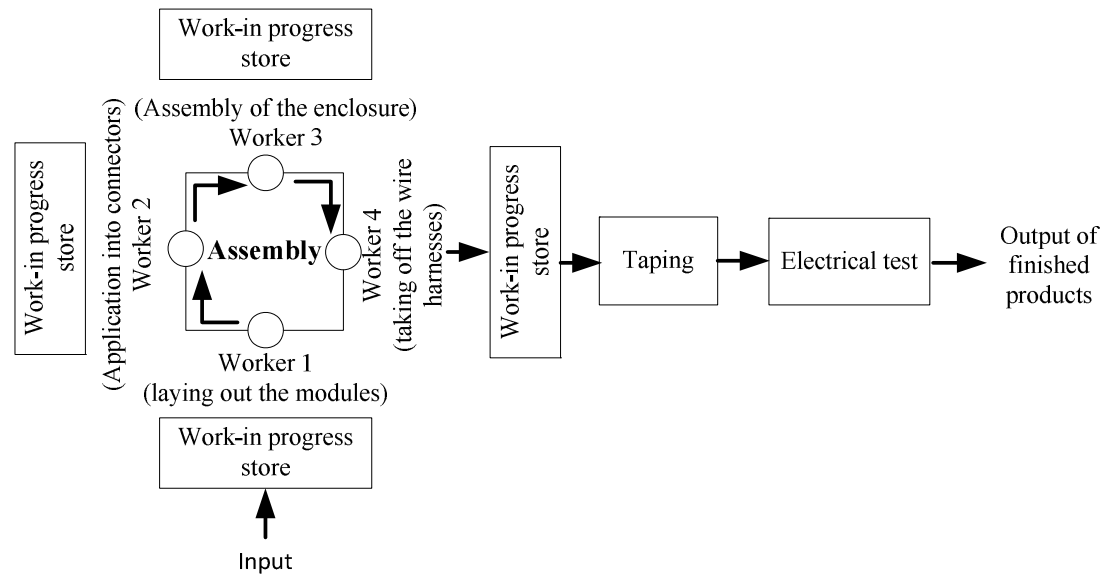

Fig. 3. Material flow in the assembly centre

Assembly operations are performed on a rotary table by three workers. Worker 1 lays out the prepared modules on the assembly table in accordance with the drawing of the product to be assembled, which is shown on the table. Worker 2 applies two additional wires into connectors, while Worker 3 inserts modules into enclosures. The wire harnesses are then taken from the table and transferred for the taping operation, after which an electrical test is carried out. If one of the modules or additional wires was not installed correctly, the product is considered defective.

All assembly operations require precision and high skills of the workers. An incorrect arrangement of modules causes a significant extension of time for application of additional wires in the subsequent operation. Both the operation of laying out the modules and taking off the wiring harnesses must be performed very carefully because the wires may slip out from the connectors or enclosure. Because final assembly centres operate on the principle of a swivel, the skills of the operators re very important as they need to work with the same pace. 


\subsection{The Purpose and Method of Building the Artificial Neural Network}

The purpose of building the artificial neural network was to ensure the stability of a wiring harness assembly process. An assembly process can be deemed stable, if the production volume during a shift is consistent with the adopted production plan. Otherwise, corrective actions, which consist in changing the values of input parameters of the production resources used in the process, should be taken.

The assembly time of a wiring harness depends primarily on the number of the modules it consists of. This is associated both with the fact that more elements need to be assembled and taped. The boundaries of stability and the productivity of the assembly process for different numbers of modules were determined. These values are presented in Table 1.

Table 1. The productivity and the ranges of stability in the wiring harness assembly process depending on the number of modules

\begin{tabular}{|c|c|c|}
\hline $\begin{array}{c}\text { Number of modules in } \\
\text { the wiring harness } \\
{[\mathrm{pcs}]}\end{array}$ & $\begin{array}{c}\text { Production plan } \\
{[\mathrm{pcs} / \text { shift] }}\end{array}$ & $\begin{array}{c}\text { Boundaries of stability } \\
{[\mathrm{pcs} / \mathrm{shift}]}\end{array}$ \\
\hline $8-14$ & 370 & $(360-380)$ \\
\hline $14-20$ & 350 & $(340-360)$ \\
\hline $21-25$ & 320 & $(310-330)$ \\
\hline $26-30$ & 300 & $(290-310)$ \\
\hline
\end{tabular}

Basing on an observation of the process, an analysis of the documentation and interviews with the workers, it has been found that the factors affecting the assembly process include experience and skills of the workers designated in Fig. 3 as Workers $1,2,3$ and 4 . Therefore, the absences and turnover of workers are the factors that disturb the course of the assembly process the most. A new worker slows down the operation of an entire assembly centre and increases the number of defective elements found. It has been found that a new worker is able to acquire an adequate efficiency only after 1 month of work at a given assembly centre.

In order to predict the quantity of the products produced at the input parameters set, a unidirectional neural network (multilayer perceptron) was built. The quantity of assembled wiring harnesses of good quality, i.e. those which passed the electrical test successfully, was to be the dependent variable. The independent variables were selected as follows:

$\mathrm{X}_{1}$ - the number of modules in the wire harness,

$\mathrm{X}_{2}$ - the skills level of Worker 1 ,

$\mathrm{X}_{3}$ - the skills level of Worker 2,

$\mathrm{X}_{4}$ - the skills level of Worker 3,

$\mathrm{X}_{5}$ - the skills level of Worker 4 ,

$\mathrm{X}_{6}$ - taping time,

$\mathrm{X}_{7}$ - the number of defective elements detected at the electrical test station. 
In order to evaluate the parameter of workers' skills levels, 4 values have been introduced:

1 - a worker who works less than 1 week,

2 - a worker who works less than 2 week,

3 - a worker who works less than 4 week,

4 - an experienced worker.

The data were collected from observations and measurements of an actual process as well as from the analysis of the organizational documentation and quality control reports. In total, 378 measurements were available for each variable. This set was divided into two parts, one of which served as a training set, while the second part was used for testing the network.

The experiment was performed in the SAS Enterprise Miner 6.2 environment. The first step was to investigate the correlation between independent variables and the dependent variable. The results containing the correlation value are shown in Table 2 .

Table 2. The values of the correlation between variables

\begin{tabular}{|l|c|}
\hline \multicolumn{1}{|c|}{ Independent attribute (variable) } & Correlation value \\
\hline number of modules in the wiring harness & 0.16583 \\
\hline the skills level of Worker 1 & -0.16872 \\
\hline the skills level of Worker 2 & -0.22465 \\
\hline the skills level of Worker 3 & -0.14535 \\
\hline the skills level of Worker 4 & 0.03276 \\
\hline taping time & 0.02104 \\
\hline $\begin{array}{l}\text { the number of defective elements detected at the elec- } \\
\text { trical test station }\end{array}$ & -0.02957 \\
\hline
\end{tabular}

The obtained results indicate that it is pointless to use a linear regression method (absolute values of the correlation are below 0.5 ) for the analysed problem. Therefore it is justified to the use neural networks which build non-linear regression models.

As a part of further experiments, a model of a multilayer perceptron network was built, for which the values of the number of neurons in the hidden layer were changed. In order to confirm the results of the correlation analysis, a neural network according to the generalized linear model was also built.

For the neural network models built, a series of experiments for different numbers of independent variables was performed. Their goal was to establish the combination of independent variables, for which the neural network will provide the best prediction of the number of wiring harnesses manufactured per shift. When building the models, different numbers of independent variables were considered. Their selection was dictated by previous experiments, i.e. it depended on the absolute value of the correlation (see: Table 2). Under the experiment no. 1, all input attributes were used, while in the experiment no. 2 the 'taping time' attribute (the lowest absolute value of the correlation) was discarded. In the experiment no. 3 the 'number of defective elements found at the electrical test station' attribute (the next lowest absolute value of the correlation) was discarded in addition. The results are presented in Table 3, where 
the values obtained represent a network selection criterion, which is a mean square error. These results concern the analysis of the input data set, which was also used for network training process.

Table 3. The results of the experiments for different variants of the neural network built

\begin{tabular}{|l|c|c|c|c|}
\hline \multirow{2}{*}{$\begin{array}{c}\text { Model of the } \\
\text { neural } \\
\text { network }\end{array}$} & \multicolumn{4}{|c|}{ Mean squared error } \\
\cline { 2 - 5 } & $\begin{array}{c}\text { Experiment } \\
\text { No. 1 }\end{array}$ & $\begin{array}{c}\text { Experiment } \\
\text { No. 2 }\end{array}$ & $\begin{array}{c}\text { Experiment } \\
\text { No. 3 }\end{array}$ & $\begin{array}{c}\text { Experiment } \\
\text { No. 4 }\end{array}$ \\
\hline MPN - NN=3 & 999.05 & 2443.71 & 1056.1 & 427.08 \\
\hline MPN - NN=16 & 2537.86 & 1369.98 & 1437.86 & 1019.25 \\
\hline MPN - NN=32 & 327.08 & 767.69 & 375.39 & 526.14 \\
\hline MPN - NN=48 & 1219.25 & 754.22 & $\mathbf{3 2 7 . 1 5}$ & 2088.12 \\
\hline MPN - NN=64 & 2375.39 & 872.49 & 999.05 & 368.14 \\
\hline GLM & 1851.50 & 1450.28 & 1851.50 & 2569.8 \\
\hline
\end{tabular}

Where MPN - a multilayer perceptron network,

$\mathrm{NN}$ - number of neurons in the hidden layer,

GLM - generalized linear model.

The analysis of the results confirms that linear models are not suitable for solving this problem. For each experiment, the worst results (with the highest mean square error) were obtained for a neural network built according to the generalized linear model. The best results were obtained for a multilayer perceptron network with 48 neurons under the experiment no. 3, a schematic diagram of which is shown in Fig. 4.

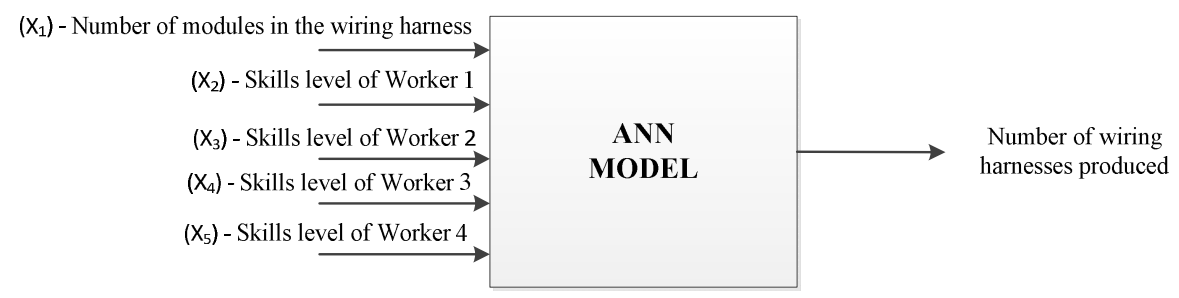

Fig. 4. Independent variables and the dependent variable used to build the artificial neural network (ANN)

The ANN model presented in Fig. 4 was used for further experiments, i.e. to assess the stability of the wiring harness assembly process for different values of independent variables.

\subsection{Determination of the Stability of the Wiring Harness Assembly Process Using a Neural Network with 48 Neurons in the Hidden Layer}

In order to determine the stability of the analysed process, test data were prepared and the "score" node of the SAS Enterprise Miner 6.2 environment was used. The test data 
contained various variants of changes in input attributes (independent variables). For such data, the selected neural network model predicts the values for the manufactured wiring harnesses, which are interpreted in the context of the stability of the assembly process. Sample test data along with the predicted number of manufactured elements are presented in Błąd! Nie można odnaleźć źródła odwołania., and Table 5.

The purpose of the experiment no. 1 was to examine how the skills levels of the workers at the assembly centre affect the stability of the analysed process. For example, a wiring harness with 12 modules was selected. The production plan for wiring harnesses consisting of 12 modules is at the level of $370 \mathrm{pcs} / \mathrm{shift}$. For the needs of the study it has been assumed that the production process is stable, if the absolute value of the difference between the quantity assumed in the production plan and the quantity produced does not exceed $20 \mathrm{pcs} / \mathrm{shift}$, i.e. is within the range $(360-380 \mathrm{pcs}$ of wiring harnesses per shift). Błąd! Nie można odnaleźć źródła odwołania. shows that the production volume predicted by the ANN model depends on the skills level of Worker 3, assuming that the level of skills of other workers is high.

Table 4. The predicted production volume for different skills levels of Worker 3 and a fixed number of modules to be assembled

\begin{tabular}{|c|c|c|c|c|c|}
\hline \multicolumn{7}{|c|}{ Network inputs } & $\begin{array}{c}\text { Network } \\
\text { outputs }\end{array}$ \\
\hline $\begin{array}{c}\text { Number } \\
\text { of mod- } \\
\text { ules } \\
{[\mathrm{pcs}]}\end{array}$ & $\begin{array}{c}\text { Skills level } \\
\text { of Worker 1 }\end{array}$ & $\begin{array}{c}\text { Skills level } \\
\text { of Worker } \\
2\end{array}$ & $\begin{array}{c}\text { Skills level } \\
\text { of Worker 3 }\end{array}$ & $\begin{array}{c}\text { Skills level } \\
\text { of Worker 3 }\end{array}$ & $\begin{array}{c}\text { Predicted } \\
\text { production } \\
\text { volume }\end{array}$ \\
\hline 12 & 4 & 4 & 4 & 3 & 370 \\
\hline 12 & 4 & 4 & 3 & 3 & 362 \\
\hline 12 & 4 & 4 & 2 & 3 & 341 \\
\hline 12 & 4 & 4 & 1 & 3 & 289 \\
\hline
\end{tabular}

The data included in Błąd! Nie można odnaleźć źródła odwołania. are presented additionally in the context of the process stability in Fig. 5.

As it results from Błąd! Nie można odnaleźć źródła odwołania. and Fig. 5, the process loses the steady state, if Worker 3 works for a period shorter than two weeks. This result confirms the observations made when collecting the data and analysing the process. It also confirms the opinions of the workers and process managers that only after a month of performing assembly operations, a new employee is able to work in accordance with the pace adopted for the assembly centre, and the number of defective products returns to the assumed level.

The purpose of the next experiment was to check whether the stability of the process would be similar for a larger number of modules in a wiring harness and at the same skills levels of the workers. A wiring harness consisting of 28 modules was used as an example. The production plan for this product was at the level of $300 \mathrm{pcs}$ per shift, while the boundaries of the process stability were set at $290-310 \mathrm{pcs} / \mathrm{shift}$. 
Table 6Błąd! Nie można odnaleźć źródła odwołania. presents the production volume predicted by the ANN model for these assumptions.

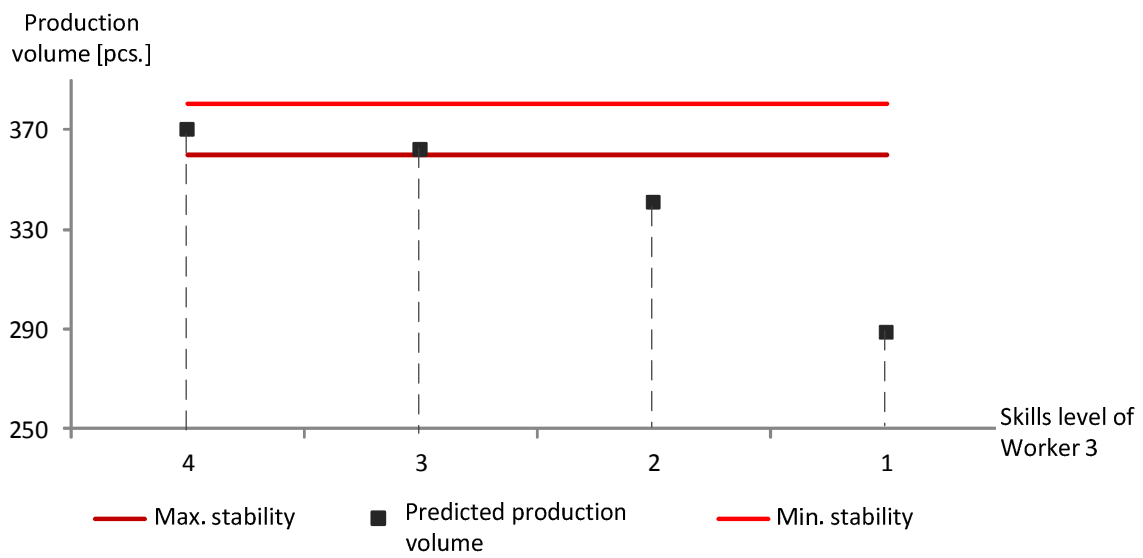

Fig. 5. The predicted production volume of wiring harnesses for a fixed number of modules and different skills levels of Worker 3

Table 5. The predicted production volume of wiring harnesses with 28 modules for different skills levels of Worker 3

\begin{tabular}{|c|c|c|c|c|c|}
\hline \multicolumn{5}{|c|}{ Network inputs } & $\begin{array}{c}\text { Network } \\
\text { outputs }\end{array}$ \\
\hline $\begin{array}{c}\text { Number } \\
\text { of mod- } \\
\text { ules } \\
\text { [pcs] }\end{array}$ & $\begin{array}{c}\text { Skills level } \\
\text { of Worker 1 }\end{array}$ & $\begin{array}{c}\text { Skills level } \\
\text { of Worker 2 }\end{array}$ & $\begin{array}{c}\text { Skills level } \\
\text { of Worker 3 }\end{array}$ & $\begin{array}{c}\text { Skills level } \\
\text { of Worker 3 }\end{array}$ & $\begin{array}{c}\text { Predicted } \\
\text { production } \\
\text { volume }\end{array}$ \\
\hline 28 & 4 & 4 & 4 & 3 & 308 \\
\hline 28 & 4 & 4 & 3 & 3 & 288 \\
\hline 28 & 4 & 4 & 2 & 3 & 225 \\
\hline 28 & 4 & 4 & 1 & 3 & 162 \\
\hline
\end{tabular}

The data included in Błąd! Nie można odnaleźć źródła odwołania. are presented additionally in the context of the process stability in Fig. 6.

As it appears from Błąd! Nie można odnaleźć źródła odwołania. and Fig. 6 at the same skills levels of the workers but for an increased number of modules in a wiring harness, the process is stable only if all workers at the assembly centre are experienced, i.e. work at this centre for more than 4 weeks. If Worker 3 works at this centre for a period shorter than 4 weeks, the process is no longer stable. The results of the experiment confirm the observations and previous assumptions that only experienced workers (i.e. those who work at a given centre for more than 4 weeks) are able to work in accordance with the adopted pace, and the number of defective elements manufactured by them decreases to a minimum. 


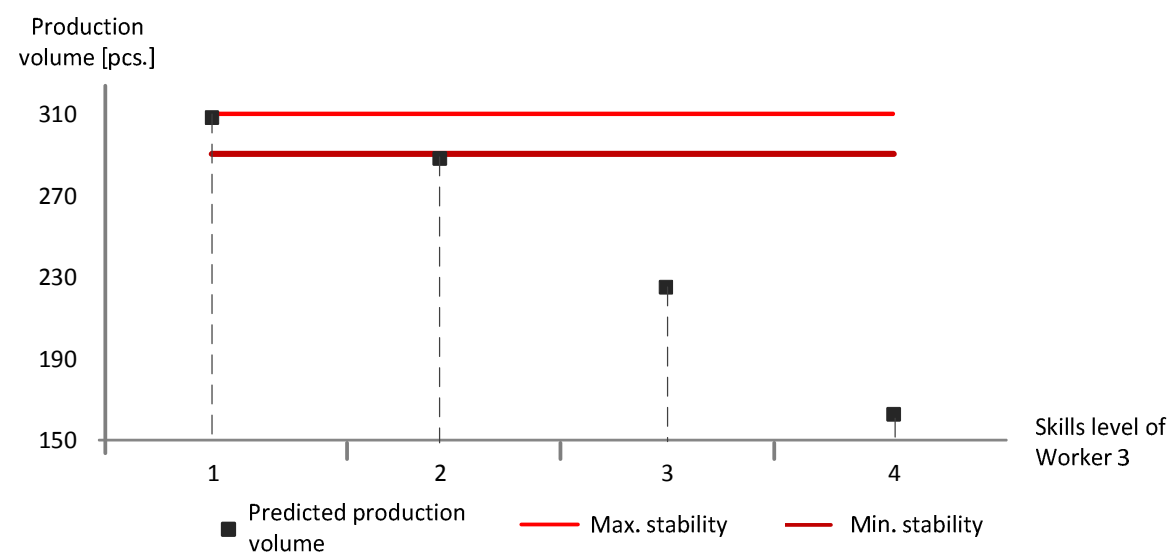

Fig. 5. The predicted production volume for wiring harnesses with 28 modules for different skills levels of Worker 3

\section{Summary}

Models of artificial neural networks can be used to control a production system, and thus to ensure its stability. Such models are very useful tools, because they can be built quickly and easily. The only issue is a large amount of data needed in the neural network training process. However, in the era of common availability of IT systems, the parameterization and standardization of production processes is not a problem anymore.

The development of IT systems led to an increase in the amount of information collected in enterprises. In turn, the market requirements and the dynamics of the business environment caused that new, faster methods of production system modelling are searched for. Such methods include models of artificial neural networks, which provide solutions that take into account the process of training on the basis of available data. They allow skipping the stage of modelling complex relationships between elements of a production system. In order to build a model of a production system, it is enough to define the problem, select input and output variables, and prepare a training data set.

Artificial neural networks (ANN) constitute a modern method for mathematical modelling of phenomena and processes, which in the last dozen or so years found many applications in different areas of human activity. The reason why ANN are used in the science and engineering is the possibility to treat dynamic, complex variables or imprecisely defined processes as a black box. In other words, ANN allow finding a relationship between many input variables and the output variable in the process without a need to build complex mathematical equations. 


\section{References}

1. Bilski, J.: The UD RLS algorithm for training feedforward neural networks. International Journal of Applied Mathematics and Computer Science 15(1), 115-123 (2005)

2. Bilski, J., Rutkowski, L.: A fast training algorithm for neural networks. IEEE Trans. Circuits Syst. II 45(6), 749-753 (1998)

3. Burduk, A., Chlebus, E.: Methods of risk evaluation in manufacturing systems. Archives of Civil and Mechanical Engineering 9(3), 17-30 (2009)

4. Frumusanu, G., Epureanu, A., Ionut, C.: Cutting process stability evaluation by process parameters monitoring. In: NOLASC 2009 Proceedings of the 8th WSEAS International Conference on Non-linear Analysis, Non-linear Systems and Chaos, vol. 1, pp. 345-350 (2009)

5. Chlebus, E., Burduk, A., Kowalski, A.: Modelling and computer simulation as tools for reorganization of production processes. In: HAIS 2011 Proceedings of the 6th International Conference Hybrid Artificial Intelligent Systems, Wroclaw, Poland (2011)

6. Chlebus, T., Stefaniak, P.: The concept of intelligent system for horizontal transport in a copper ore mine. In: Corchado, E., Snášel, V., Abraham, A., Woźniak, M., Graña, M., Cho, S.-B. (eds.) HAIS 2012, Part II. LNCS, vol. 7209, pp. 267-273. Springer, Heidelberg (2012)

7. Mahmood, K., Zidouri, A., Zerguine, A.: Performance analysis of a RLS-based MLP-DFE in time-invariant and time-varying channels. Digital Signal Processing 18, 307-320 (2008)

8. Sankar, N., Prabhu, B.: Modified approach for prioritization of failures in a system failure mode and effects analysis. International Journal of Quality \& Reliability Management 18(3), 324-336 (2001)

9. Rutkowski, L.: Methods and Techniques of Arificial Inteligence. PWN, Warszawa (2009)

10. Wieczorek, T.: Neural models of technological processes, Monograph. Publishing House of the Silesian University of Technology, Gliwice (2008)

11. Tung-Hsu, H., Wang-Lin, L., Li, L.: Intelligent remote monitoring and diagnosis of manufacturing processes using an integrated approach of neural networks and rough sets. Journal of Intelligent Manufacturing 18(2), 239-253 (2003) 